This is a post-peer-review, pre-copyedit version of an article published in Clinical Drug Investigation. The final authenticated version is available online at: https://doi.org/10.1007/s40261-017-0597-x 


\section{Burden of disease of Human Papillomavirus (HPV): hospitalizations in Marche and Veneto regions. An observational study}

Short Title: Economic burden and hospitalization rates due to HPV in Italy, a regional analysis

Authors: Francesco S. Mennini ${ }^{1,2}$, Gianluca Fabiano ${ }^{1,2}$, Andrea Marcellusi ${ }^{1,2,3}$, Paolo Sciattella ${ }^{1}$, Mario Saia ${ }^{4}$, Silvia Cocchio ${ }^{5}$, Vincenzo Baldo ${ }^{5}$

${ }^{1}$ Economic Evaluation and HTA (EEHTA), CEIS, Faculty of Economics, University of Rome "Tor Vergata", Italy.

2 Institute of Leadership and Management in Health, Kingston University, London,UK

${ }^{3}$ Consiglio Nazionale delle Ricerche (CNR), Istituto di Richerche sulla Popolazione e le Politiche Sociali (IRPPS), Rome, Italy

${ }^{4}$ Net, Veneto Region Health Directorate, Venezia, Italy.

${ }^{5}$ Hygiene and Public Health Unit, Department of Cardiac, Thoracic and Vascular Sciences, University of Padua

Francesco Saverio Mennini

Address: Via Columbia, 2. Roma (RM)

Tel: +39 3208964196

E-mail: f.mennini@uniroma2.it

\section{Gianluca Fabiano}

Address: Via Columbia, 2. Roma (RM)

Tel: +39 3395785394

E-mail: gia.fabiano@gmail.com

\section{Andrea Marcellusi}

Address: Via Columbia, 2. Roma (RM)

Tel: +393492748592

Fax: +3906233245 53

E-mail: andrea.marcellusi@uniroma2.it

\section{Sciattella Paolo}

Address: Via Columbia, 2. Roma (RM)

Tel: +39

E-mail:

\section{Saia Mario,}

Net, Veneto Region Health Directorate, Venezia, Italy.

Saia.mario@regione.veneto.it

\section{Silvia Cocchio}

Institute of Hygiene, University of Padua Via Loredan, 18, 35121 Padova, Italy

E-mail: silvia.cocchio@unipd.it 


\section{Baldo Vincenzo}

Institute of Hygiene, University of Padua Via Loredan, 18, 35121 Padova, Italy E-mail: Vincenzo.baldo@unipd.it

Keywords: cost of illness; HPV; direct cost; claims database; Italy. 


\section{Burden of disease of human Papillomavirus (HPV): hospitalizations in Marche and Veneto regions. An observational study}

\section{Abstract:}

Background and Objectives: HPV (Human Papillomavirus) is the most often responsible virus for sexually transmitted infections. The burden of HPV-related diseases on hospital resources represents a major public health problem. The aim of this study was to assess the economic burden of HPV-related diseases (Anal cancer, Genital cancer, Genital warts, Oropharyngeal cancer) on hospitals resources in two Italian regions. Methods: a retrospective, non-randomized, observational study was developed in Marche and Veneto Regions, based on patients receiving hospitalization between 2008 and 2011. All hospitalizations were identified through administrative archives, according to the International Classification of Diseases (ICD-9 CM) to which a defined tariff was assigned. Results: we identified 5,299 hospitalized patients in Veneto and 1,735 in Marche Region. The mean annual hospitalization rate was 49.44 per 100,000 individuals in Veneto and 48.41 in Marche. The total mean annual cost attributable to HPV-related diseases was $€ 5,78(S D 0,80)$ million in Veneto and $€ 2,24$ (SD 0.17) million in Marche. Costs associated with genital cancer amounted to $€ 1,61$ million in Veneto and $€ 1,06$ million in Marche ( $28 \%$ and $47 \%$ of total mean annual cost respectively). Oropharyngeal cancer accounted for 36\% in Veneto ( $€ 2,08$ million) and $28 \%$ in Marche ( $€ 632,645$ ). Hospitalization costs related to Anal cancer were $€ 882,567$ in Veneto and $€ 377,719$ in Marche; Genital warts accounted for $€ 1,19$ million in Veneto and $€ 171,406$ in Marche. Finally, the mean cost per patient was $€ 4,364$ in Veneto and $€ 5,176$ in Marche. Conclusions: The present work estimated the cost of HPV-related diseases for hospitalized patients in two Italian regions. The considerable estimated annual economic burden is a powerful driver for the governance of the public health sector.

\section{Key Points:}

1) The economic burden and hospitalization rates associated with HPV-related diseases were estimated from a regional perspective in Italy.

2) Between 2008 and 2011 resources allocated and hospitalization rates highlighted a decreasing trend in both Veneto and Marche regions.

3) Over $72 \%$ of hospital admissions were strictly linked to HPV and caused a mean annual burden of $€ 3,89$ million in Veneto and $€ 1,60$ million in Marche.

\section{Background and Objectives:}

HPV (Human Papillomavirus) is the most often responsible virus for sexually transmitted infection. As of today, more than 100 types of papillomavirus infecting human beings have been identified. Of these, about $40 \%$ are associated with a wide range of genital diseases [1]. It was estimated that about $75 \%$ of sexually-active women are infected with any type of HPV virus during their lifetime [2]. Most infections are transient and asymptomatic however, in some cases, HPV involves a highoncogenic risk associated with the onset of cancers. When this happens the infection can progress to pre-cancerous and cancerous lesions. In particular, genotypes 16 and 18 are highly-risky virus variances, causing $70 \%$ of invasive cervical cancer and dysplasia globally $[3,4]$. Overall, HPV virus is 
responsible for $88 \%$ of anal cancers in both sexes, $70 \%$ of vaginal cancers, $43 \%$ of vulvar cancers and $50 \%$ of penis cancers [5].

Many studies have been conducted in Italy on the prevalence and incidence of HPV infections [6-8]. However, these works often reported heterogeneous data due to the different populations analysed. Therefore, as of today there are no epidemiological studies taking into account a representative sample of the whole Italian population. A systematic revision of the literature tried to systematize the available epidemiological and economic information in the specific national context, estimating an annual direct cost associated with the main HPV-related diseases higher than $€ 528,6$ million (€ 480,1 - $€ 686,2$ million range) [4]. A study conducted in Veneto examining the hospitalization rates of the different HPV-related diseases in a cohort of 5 million citizens showed that the burden of HPV-related diseases on hospital resources is a major public health problem [3].

The objective of this study was to estimate the overall and average economic impact per patient in two Italian regions, Veneto and Marche, between 2008 and 2011. For this purpose, hospitalizations associated with HPV-related diseases were analysed based on the administrative data of the two examined regions.

\section{Methods:}

This is an observational retrospective study based on data extracted from the health information system of Veneto and Marche regions. Hospital discharge record (HDR) referred to the period 20082011 were analysed in order to identify hospitalization rates and the costs associated with HPVrelated diseases. Information related to the hospital discharges of all accredited public and private hospitals in Veneto and Marche, both in ordinary and day-care regime, were taken into account.

Total costs related to hospitalizations were calculated using the diagnosis-related groups (DRGs) of hospitalized patients at the time of their discharge based on their age, gender and the consumption of resources during their hospital stay. According to the DRG-based reimbursement system, every hospitalized patient was attributed to a group of diagnostically homogeneous cases so that patients with the same DRG were assigned the same reimbursement charges. Specifically, we included hospitalizations related to resident patients in Veneto or Marche region, aged $\geq 18$ and presenting one of the following International Classification of Diseases, 9th revision - Clinical Modification (ICD9-CM) codes as primary or secondary diagnosis: Genital warts: "Condyloma acuminatum" (078.11); "Anal cancers" (154.2-154.8); Oropharyngeal cancers: "Oropharyngeal cancer" (146.0-146.9) and "Head, face and neck cancers" (171.0); Genital cancers: "Penis cancer" (187.1-187.9) and "Cervical cancer" (180.0-180.9).

HPV-related hospitalization rates referred to the overall population were calculated comparing the number of hospitalized patients, broken down by type and age, to the corresponding resident population at the beginning of the discharge year [9].

In addition, a further estimation of the hospitalization rates and costs strictly linked to the presence of the HPV virus, was calculated by applying diagnosis-specific weights obtained from literature (Table 1). Specifically, it was assumed that $100 \%$ of the hospitalizations due to "Condiloma acuminatum" (Genital warts) $[10,11]$ and "Cervical cancers" were strictly associated with HPV [1, 12] compared to $50 \%$ of hospitalizations due to "Penis cancer" [5], 77\% to "Anal cancer" [5], and $26 \%$ to "Oropharyngeal cancer" [13]. The diagnosis-specific weights were applied to the 
hospitalizations per single diagnosis and this allowed our analysis to obtain a more specific estimation of the economic burden strictly related to HPV virus.

The data analysis was generated using SAS software, Version 9.2 of the SAS System for Windows, Copyright (C) 2002-2008 SAS Institute Inc. (SAS Institute, 2008). Personal data were replaced with a random series of codes, in order to anonymize the database in compliance with the Italian privacy law.

Table 1: weights used for HPV-strictly related diseases calculation

\begin{tabular}{cclcl} 
Diagnosis & Male & Ref. & Female & \multicolumn{1}{c}{ Ref. } \\
\hline \hline Anal cancer & $77 \%(66 \%-88 \%)$ & {$[14]$} & $77 \%(66 \%-88 \%)$ & {$[14]$} \\
Genital cancer & $52 \%(37,6 \%-66 \%)$ & {$[14]$} & $100 \%$ & {$[1,12]$} \\
Genital warts & $100 \%$ & {$[10,11]$} & $100 \%$ & {$[10,11]$} \\
Oropharyngeal cancer & $26 \%(24 \%-27 \%)$ & {$[13]$} & $26 \%(24 \%-27 \%)$ & {$[13]$}
\end{tabular}

\section{Results:}

A total of 10,586 hospitalizations was recorded between 2008 and 2011 in Veneto and Marche region, 8,044 (76\%) and 2,542 (24\%) respectively. Overall, $45.7 \%$ were referred to male patients, while $54.3 \%$ to females. In Table 2, hospitalizations are reported by age, sex and diagnosis for each region separately. 
Table 2: HPV-related hospitalizations in Veneto and Marche (2008-2011)

\begin{tabular}{|c|c|c|c|c|c|c|c|c|c|c|}
\hline \multirow[b]{2}{*}{ VENETO } & \multicolumn{2}{|c|}{$\begin{array}{c}\text { Total } \\
\mathrm{N}=8,044\end{array}$} & \multicolumn{2}{|c|}{$\begin{array}{c}\text { Anal } \\
\text { cancer } \\
\mathrm{N}=\mathbf{1 , 0 1 6}\end{array}$} & \multicolumn{2}{|c|}{$\begin{array}{c}\text { Genital } \\
\text { cancer } \\
\mathrm{N}=\mathbf{1 , 7 4 2}\end{array}$} & \multicolumn{2}{|c|}{$\begin{array}{c}\text { Genital } \\
\text { warts } \\
N=2,647\end{array}$} & \multicolumn{2}{|c|}{$\begin{array}{c}\text { Oropharyngeal } \\
\text { cancer } \\
N=2,639 \\
\end{array}$} \\
\hline & $n$ & $\%$ & $\mathbf{N}$ & $\%$ & $n$ & $\%$ & $n$ & $\%$ & $\mathrm{n}$ & $\%$ \\
\hline \multicolumn{11}{|l|}{ Sex } \\
\hline Males & 3,857 & 47.9 & 488 & 48.0 & 376 & 21.6 & 971 & 36.7 & 2,022 & 76.6 \\
\hline Females & 4,187 & 52.1 & 528 & 52.0 & 1,366 & 78.4 & 1,676 & 63.3 & 617 & 23.4 \\
\hline \multicolumn{11}{|l|}{ Age group } \\
\hline $18-24$ & 571 & 7.1 & 1 & 0.1 & 12 & 0.7 & 547 & 20.7 & 11 & 0.4 \\
\hline $25-44$ & 2,115 & 26.3 & 66 & 6.5 & 406 & 23.3 & 1,570 & 59.3 & 73 & 2.8 \\
\hline $45-64$ & 2,882 & 35.8 & 340 & 33.5 & 713 & 40.9 & 452 & 17.1 & 1,377 & 52.2 \\
\hline $65-74$ & 1,414 & 17.6 & 274 & 27.0 & 297 & 17.0 & 54 & 2.0 & 789 & 29.9 \\
\hline $75-84$ & 817 & 10.2 & 228 & 22.4 & 254 & 14.6 & 22 & 0.8 & 313 & 11.9 \\
\hline \multirow[t]{2}{*}{$85+$} & 245 & 3.0 & 107 & 10.5 & 60 & 3.4 & 2 & 0.1 & 76 & 2.9 \\
\hline & \multicolumn{2}{|c|}{$\begin{array}{c}\text { Total } \\
\mathrm{N}=\mathbf{2 , 5 4 2}\end{array}$} & \multicolumn{2}{|c|}{$\begin{array}{c}\text { Anal } \\
\text { cancer } \\
\mathrm{N}=362\end{array}$} & \multicolumn{2}{|c|}{$\begin{array}{c}\text { Genital } \\
\text { cancer } \\
\mathrm{N}=\mathbf{1 , 2 3 0}\end{array}$} & \multicolumn{2}{|c|}{$\begin{array}{c}\text { Genital } \\
\text { warts } \\
\mathrm{N}=442 \\
\end{array}$} & \multicolumn{2}{|c|}{$\begin{array}{c}\text { Oropharyngeal } \\
\text { cancer } \\
\mathrm{N}=508\end{array}$} \\
\hline MARCHE & $\mathrm{n}$ & $\%$ & $\mathbf{N}$ & $\%$ & $\mathbf{n}$ & $\%$ & $\mathbf{n}$ & $\%$ & $\mathbf{n}$ & $\%$ \\
\hline \multicolumn{11}{|l|}{ Sex } \\
\hline Males & 981 & 38.6 & 187 & 51.7 & 209 & 17.0 & 203 & 45.9 & 382 & 75.2 \\
\hline Females & 1561 & 61.4 & 175 & 48.3 & 1021 & 83.0 & 239 & 54.1 & 126 & 24.8 \\
\hline \multicolumn{11}{|l|}{ Age group } \\
\hline $18-24$ & 123 & 4.8 & 0 & 0 & 7 & 0.6 & 100 & 22.6 & 16 & 3.1 \\
\hline $25-44$ & 673 & 26.5 & 32 & 8.8 & 352 & 28.6 & 261 & 59.0 & 28 & 5.5 \\
\hline $45-64$ & 890 & 35.0 & 134 & 37.0 & 482 & 39.2 & 68 & 15.4 & 206 & 40.6 \\
\hline $65-74$ & 439 & 17.3 & 101 & 27.9 & 191 & 15.5 & 10 & 2.3 & 137 & 27.0 \\
\hline $75-84$ & 310 & 12.2 & 69 & 19.1 & 155 & 12.6 & 2 & 0.5 & 84 & 16.5 \\
\hline $85+$ & 107 & 4.2 & 26 & 7.2 & 43 & 3.5 & 1 & 0.2 & 37 & 7.3 \\
\hline
\end{tabular}

Between 1st January 2008 and 31st December 2011 7,034 patients were hospitalized with potential HPV-related diseases: 5,299 in Veneto (75.3\%) and 1,735 in Marche (24.7\%). Every year about 1,325 patients were hospitalized in Veneto and 434 in Marche. The most frequent diseases were genital warts in Veneto (2,275 patients) and genital cancer in Marche (728 patients).

On average, from 2008 to 2011, 1.68 hospitalizations per patient were estimated in Marche and 1.47 in Veneto. The majority of hospitalizations in Marche were due to genital cancer (1.69 mean hospitalizations per patient), while in Veneto to oropharyngeal cancer with a mean of 1.96 hospitalizations per patient.

\subsection{Hospitalization rates:}

Hospitalization rates on the overall population were obtained reporting the number of hospitalized patients on the resident population in each region. The average hospitalization rate per year over the period 2008-2011 was 49.4 per 100,000 individuals in Veneto, and 48.4 per 100,000 individuals in Marche. Overall, a decreasing trend was estimated: in Veneto there were 57.2 hospitalizations per 100,000 individuals in 2008, versus 39.7 in 2011 and a similar trend was reported in Marche that passed from a rate of 52.5 hospitalizations in 2008 to 44.9 per 100,000 individuals in 2011 (Table 3). 
Table 3: Hospitalization rates per 100,000 individuals (Marche, Veneto)

$\begin{array}{lllll}2008 & 2009 & 2010 & 2011 & \text { TOT }\end{array}$

VENETO

\begin{tabular}{lrrrrr}
\hline Population & $4,022,601$ & $4,063,041$ & $4,082,292$ & $4,103,445$ & $4,067,845$ \\
Anal cancer & 9.37 & 5.14 & 5.56 & 4.95 & 6.24 \\
Genital cancer & 11.86 & 11.72 & 11.37 & 7.92 & 10.71 \\
Genital warts & 17.15 & 18.07 & 16.44 & 13.45 & 16.27 \\
Oropharyngeal cancer & 18.77 & 17.18 & 15.58 & 13.40 & 16.22 \\
Total & 57.15 & 52.10 & 48.94 & 39.72 & 49.44
\end{tabular}

MARCHE

\begin{tabular}{lrrrrr}
\hline Population & $1,305,949$ & $1,319,368$ & $1,310,322$ & $1,315,600$ & $1,312,810$ \\
Anal cancer & 6.43 & 7.66 & 6.56 & 6.92 & 6.89 \\
Genital cancer & 24.58 & 24.03 & 22.74 & 22.35 & 23.42 \\
Genital warts & 10.41 & 8.64 & 7.48 & 7.15 & 8.42 \\
Oropharyngeal cancer & 11.03 & 7.20 & 11.91 & 8.59 & 9.67 \\
Total & 52.45 & 47.52 & 48.69 & 45.00 & 48.41
\end{tabular}

\subsection{Costs:}

Between 2008 and 2011, each treated patient caused an average annual expense, in terms of hospitalizations related to cancer, of $€ 6,063$ in Veneto and $€ 6,237$ in Marche. Regarding genital warts the mean cost per patient in Veneto was $€ 2,107$ and in Marche $€ 1,672$. In Table 3 we report the cost per patient by disease and year of analysis.

Table 4: Hospitalization costs per patient, year (Veneto, Marche 2008-2011)

Veneto

\begin{tabular}{|c|c|c|c|c|c|}
\hline Year & $\begin{array}{c}\text { Anal } \\
\text { cancer }\end{array}$ & $\begin{array}{c}\text { Genital } \\
\text { cancer }\end{array}$ & $\begin{array}{c}\text { Oropharyngeal } \\
\text { cancer }\end{array}$ & $\begin{array}{c}\text { Total } \\
\text { cancer }\end{array}$ & $\begin{array}{c}\text { Genital } \\
\text { warts }\end{array}$ \\
\hline 2008 & $€ 5,603.87$ & $€ 6,098.85$ & $€ 5,863.18$ & $€ 5,870.23$ & $€ 2,225.67$ \\
\hline 2009 & $€ 6,630.53$ & $€ 7,133.94$ & $€ 7,405.85$ & $€ 7,171.29$ & $€ 2,318.14$ \\
\hline 2010 & $€ 5,681.07$ & $€ 7,237.05$ & $€ 7,235.06$ & $€ 6,920.61$ & $€ 2,301.63$ \\
\hline 2011 & $€ 5,254.51$ & $€ 7,189.62$ & $€ 6,366.28$ & $€ 6,333.46$ & $€ 2,212.82$ \\
\hline Totale & $€ 5,732.59$ & $€ 6,862.53$ & $€ 6,658.48$ & $€ 6,523.91$ & $€ 2,267.11$ \\
\hline
\end{tabular}

Marche 


\begin{tabular}{|c|c|c|c|c|c|}
\hline Year & $\begin{array}{c}\text { Anal } \\
\text { cancer }\end{array}$ & $\begin{array}{c}\text { Genital } \\
\text { cancer }\end{array}$ & $\begin{array}{c}\text { Oropharyngeal } \\
\text { cancer }\end{array}$ & $\begin{array}{c}\text { Total } \\
\text { cancer }\end{array}$ & $\begin{array}{c}\text { Genital } \\
\text { warts }\end{array}$ \\
\hline 2008 & $€ 5,792.20$ & $€ 6,155.52$ & $€ 9,520.35$ & $€ 6,981.79$ & $€ 1,884.31$ \\
\hline 2009 & $€ 6,098.84$ & $€ 6,452.51$ & $€ 7,709.77$ & $€ 6,644.12$ & $€ 1,743.43$ \\
\hline 2010 & $€ 6,216.27$ & $€ 6,286.85$ & $€ 9,412.27$ & $€ 7,142.75$ & $€ 1,782.72$ \\
\hline 2011 & $€ 6,184.64$ & $€ 6,196.78$ & $€ 5,463.17$ & $€ 6,012.57$ & $€ 1,760.92$ \\
\hline Totale & $€ 6, \mathbf{0 7 2 . 1 1}$ & $€ 6, \mathbf{2 7 4 . 0 8}$ & $€ \mathbf{8 , 1 3 2 . 6 5}$ & $€ 6,701.67$ & $€ \mathbf{1 , 7 9 9 . 2 9}$ \\
\hline
\end{tabular}

In table 5 costs are illustrated by gender for which an independent-samples t-test was conducted to compare the mean values. A significant difference in the scores was obtained for genital cancer in both Veneto $(p=.009)$ and Marche region $(p=.004)$. In particular, in Veneto, genital warts evidenced an average cost per patient equal to $€ 4,855$ per male compared to $€ 6,870$ per female; In Marche same costs were equal to $€ 4,459$ per male and $€ 6,202$ per female, respectively.

Table 5: Hospitalization costs per patient, gender (Veneto and Marche)

\begin{tabular}{|c|c|c|c|c|c|c|}
\hline Diagnosis & \multicolumn{3}{|c|}{ Veneto } & \multicolumn{3}{c|}{ Marche } \\
\hline & Male & Female & T-test $p$ & Male & Female & $\begin{array}{c}\text { T-test } \\
p\end{array}$ \\
\hline Anal cancer & $€ 5,420.17$ & $€ 5,235.06$ & 0.868 & $€ 5,921.56$ & $€ 5,385.84$ & 0.077 \\
\hline Genital cancer & $€ 4,855.26$ & $€ 6,870.71$ & 0.009 & $€ 4,459.80$ & $€ 6,202.54$ & 0.004 \\
\hline $\begin{array}{c}\text { Oropharyngeal } \\
\text { cancer }\end{array}$ & $€ 6,227.85$ & $€ 6,061.38$ & 0.815 & $€ 7,532.15$ & $€ 7,613.35$ & 0.899 \\
\hline Total cancers & $€ \mathbf{5 , 8 5 5 . 3 9}$ & $€ \mathbf{6 , 2 9 9 . 9 5}$ & $\mathbf{0 . 3 0 6}$ & $€ \mathbf{6 , 2 5 1 . 7 5}$ & $€ \mathbf{6 , 2 2 7 . 5 6}$ & $\mathbf{0 . 9 2 9}$ \\
\hline Genital warts & $€ 2,129.08$ & $€ 2,096.07$ & 0.515 & $€ 1,647.69$ & $€ 1,692.26$ & 0.643 \\
\hline
\end{tabular}

In conclusion, the total estimate of the annual economic impact on the regional health services was calculated. As a result, hospitalizations accounted, on average, for $€ 5,78$ million (SD 0.8 ) in Veneto and $€ 2,24$ million in Marche (SD 0.17), as reported in Table 6.

Table 6: Total annual expenses due to HPV-related diseases, Veneto and Marche population (2008-10)

\begin{tabular}{|c|c|c|c|c|}
\hline 2008 & 2009 & 2010 & 2011 & Mean \\
\hline \multicolumn{5}{|c|}{ Veneto } \\
\hline$€ 6,530,353.46$ & $€ 6,142,527.60$ & $€ 5,798,918.13$ & $€ 4,657,824.46$ & $€ 5,782,405.91$ \\
\hline \multicolumn{5}{|c|}{ Marche } \\
\hline$€ 2,397,438.30$ & $€ 2,208,327.52$ & $€ 2,362,861.91$ & $€ 2,012,494.60$ & $€ 2,245,280.58$ \\
\hline
\end{tabular}


In Veneto region, the disease with the highest economic burden in terms of hospitalizations was the oropharyngeal cancer: $€ 2,08$ million corresponding to $36 \%$ of the total mean annual cost. In Marche region the highest expense was caused by genital cancers, $47 \%$ of total cost with an expense of over $€ 1,06$ million a year (Figure 1), versus $€ 1,61$ million in Veneto, about $28 \%$ of total average expenses. Furthermore, in Marche the cost of oropharyngeal cancer was estimated at $€ 632$ thousand, about $28 \%$ of the regional burden of HPV-related diseases. Anus cancer had a limited impact in Veneto, $€ 882$ thousand, corresponding to $15 \%$ of the costs incurred by the regional health service. Finally, genital warts accounted for $8 \%$ of the expenses in Marche and $21 \%$ in Veneto.

Figure 1: Expenses \% by disease on mean total (Veneto, Marche 2008-2011)

Veneto

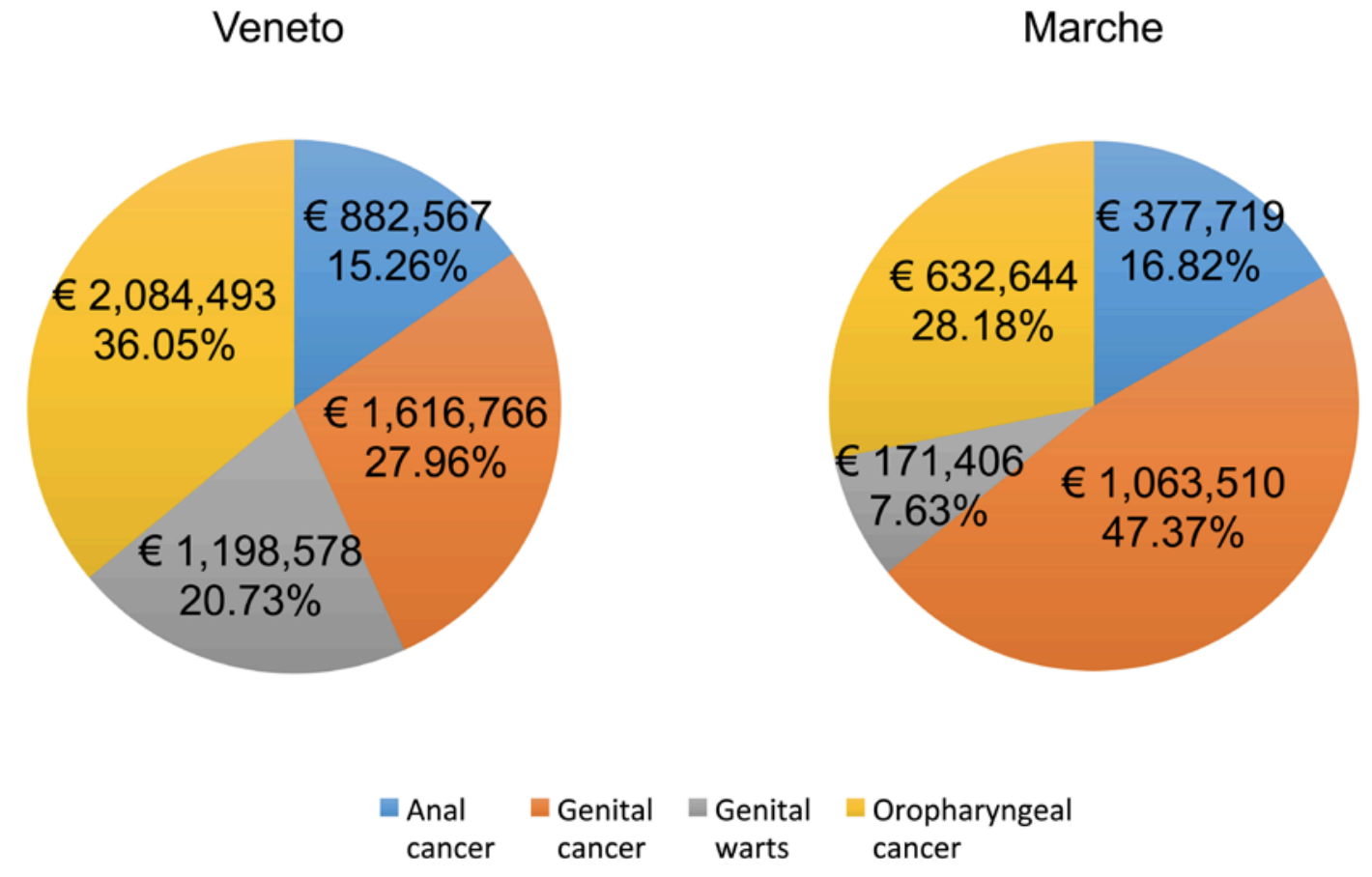

Marche

Overall, between 2008 and 2011 resources allocated to hospitalizations highlighted a decreasing trend in both regions (Figure 2). On average the study estimated a reduction of $22 \%$ between the first and the last year of analysis $(-28.67 \%$ in Veneto and $-16.06 \%$ in Marche). The decrease was higher in Veneto, especially between 2010 and 2011. 
Figure 2: total mean cost (Veneto, Marche 2008-2011)

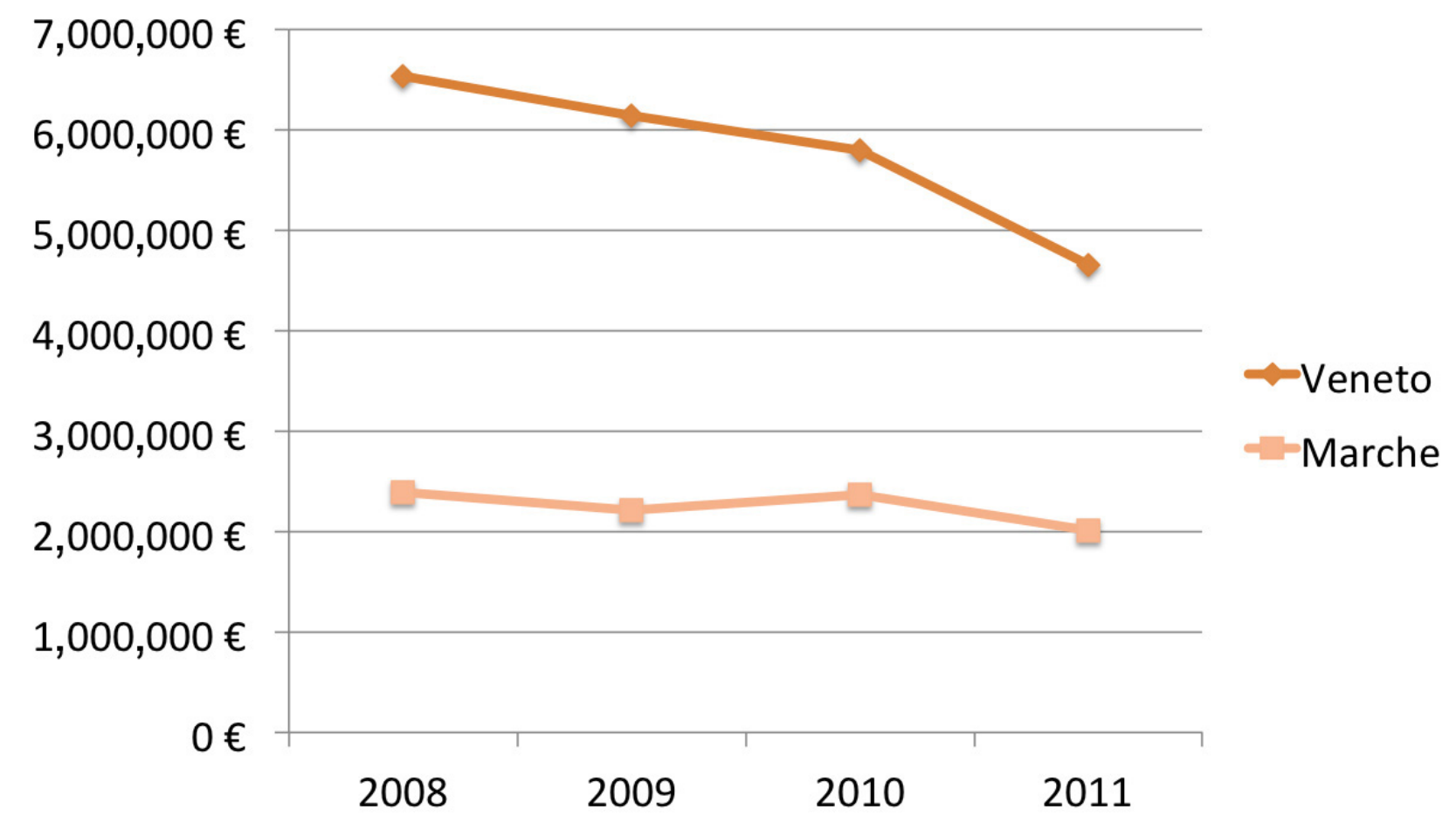

\subsection{Costs strictly related to the HPV virus:}

On average, $72 \%$ of hospitalizations were strictly related to the presence of HPV virus. As a consequence, the average economic impact of HPV strictly related diseases per year, was equal to $€ 3,89$ million in Veneto and $€ 1,60$ million in Marche (annual mean values). The disease causing higher costs in terms of hospitalizations both in Veneto and Marche was genital cancer: $€ 1,47$ million in Veneto (37.8\% of total costs) and €982,899 in Marche (61.0\%). Moreover, genital warts in Veneto caused an expense of $€ 1,19$ million, $30.8 \%$ of total cost, while anal cancer in Marche costed $€ 290,843,18,0 \%$ of mean total per year. In Table 7 the average costs per year are reported by gender and ranges as by the application of weights from literature are also illustrated. 
Table 7: Total mean cost per gender, disease (Veneto, Marche)

\begin{tabular}{|c|c|c|c|}
\hline \multicolumn{4}{|c|}{ Veneto } \\
\hline & Male & Female & Tot \\
\hline Anal cancer & $\begin{array}{c}€ 334,926 \\
(€ 287,079-€ 382,772)\end{array}$ & $\begin{array}{c}€ 344,650 \\
(€ 295,414-€ 393,886)\end{array}$ & $\begin{array}{c}€ 679,576 \\
(€ 582,494-€ 776,659)\end{array}$ \\
\hline Genital cancer & $\begin{array}{c}€ 155,931 \\
(€ 113,185-€ 198,677)\end{array}$ & $€ 1,315,740$ & $\begin{array}{c}€ 1,471,671 \\
(€ 1,428,926-€ 1,514,417)\end{array}$ \\
\hline Genital warts & $€ 415,170$ & $€ 783,407$ & $€ 1,198,578$ \\
\hline $\begin{array}{l}\text { Oropharyngeal } \\
\text { cancer }\end{array}$ & $\begin{array}{c}€ 420,597 \\
(€ 400,337-€ 440,857)\end{array}$ & $\begin{array}{c}€ 120,328 \\
(€ 114,532-€ 126,125)\end{array}$ & $\begin{array}{c}€ 540,926 \\
(€ 514,869-€ 566,982)\end{array}$ \\
\hline \multicolumn{4}{|c|}{ Marche } \\
\hline & Male & Female & Tot \\
\hline Anal cancer & $\begin{array}{c}€ 155,026 \\
(€ 132,879-€ 177,173)\end{array}$ & $\begin{array}{c}€ 135,817 \\
(€ 116,414-€ 155,219)\end{array}$ & $\begin{array}{c}€ 290,843 \\
(€ 249,294-€ 332,393)\end{array}$ \\
\hline Genital cancer & $\begin{array}{c}€ 86,631 \\
(€ 62,883-€ 110,380)\end{array}$ & $€ 896,267$ & $\begin{array}{c}€ 982,899 \\
(€ 959,150-€ 1,006,647)\end{array}$ \\
\hline Genital warts & $€ 75,793$ & $€ 95,612$ & $€ 171,406$ \\
\hline $\begin{array}{l}\text { Oropharyngeal } \\
\text { cancer }\end{array}$ & $\begin{array}{c}€ 119,718 \\
(€ 113,952-€ 125,485)\end{array}$ & $\begin{array}{c}€ 44,452 \\
(€ 42,311-€ 46,593)\end{array}$ & $\begin{array}{c}€ 164,171 \\
(€ 156,263-€ 172,079)\end{array}$ \\
\hline
\end{tabular}

Considering the weightings, hospitalization rates on the resident population that were strictly related to HPV amounted to 34.88 per 100,000 individuals in Veneto and 37.74 in Marche. Both in Veneto and Marche these rates were higher for women, 43.01 and 52.31 per 100,000 individuals respectively, compared to 26.22 of males in Veneto and 21.98 in Marche.

\section{Discussion:}

This study represents a first attempt to quantify the hospitalization rates of HPV-related diseases [3], as well as a measure of the economic burden of these hospitalizations from the Italian National Health Service perspective. At the time of the analysis, the population over 18 years old amounted to over $€ 5,3$ million, $€ 4$ million in Veneto and $€ 1,3$ in Marche that was almost $9 \%$ of the total Italian population [9]. Hence, strength of the study is constituted by the size of the population analysed especially if we consider that data are representative of all hospitals in Veneto and Marche territory. By doing so, this work represents an evolution of the previous study conducted only in Veneto[3]. Overall, the hospitalization rates of the two regions were comparable: 49.44 hospitalizations in Veneto and 48.41 in Marche per 100,000 individuals. Coherently with incidence rates reported in literature $[4,15]$, the highest hospitalization rate in Veneto was due to Genital warts (16.22 per 100,000 individuals), while in Marche genital cancers caused 23.42 hospitalized patients per 100,000 individuals. Overall, in both regions, the hospitalization rates showed a decreasing trend between 2008 and 2011 that coherently with the annual report on hospital discharges performances by the Italian Ministry of Health [16], we expect to continue in the years to come. Moreover, in coherence with the new vaccination strategy adopted in Italy (both boys and girls aged 
12) [17] and the introduction of nona-valent HPV vaccination, health gains due to primary prevention are expected to allow for further decreases [18].

In both regions, the decrease was steady during the period of analysis, even if it was higher in Veneto: $-43.88 \%$ from 2008 to 2011, compared to $-16.56 \%$ in Marche. The only disease with an opposite trend was the anus cancer that showed a slight increase of the hospitalization rates in the Marche region (6.92 in 2011 compared to 6.43 in 2008 per 100,000 individuals). In Veneto, the same disease showed a higher decrease, passing from 9.37 in 2008 to 4.95 hospitalizations per 100,000 individuals in the last year considered. In 2008 there was a higher number of secondary diagnoses compared to other years. This was due to hospitalizations related to the administration of chemotherapy that from 2007 started to be replaced by day-hospital chemotherapy treatments (Resolution of the regional Committee no. 734 of 20 March 2007: Chemotherapy and radiotherapy health services, Official Bulletin of the Veneto Region 2007. 37:106-109). The 2008 data were also due to an increase in the number of cases, as already highlighted in the previous work on Veneto [3]. In both regions the mean cost by disease was higher for malignant tumours (anus cancer, genital and oropharyngeal cancers) compared to genital warts. However, non-cancerous diseases like genital warts caused a considerable economic burden, especially in Veneto, where it was worth more than 1,19 million, $21 \%$ of the mean annual total, compared to the corresponding burden in the Marche region (about $€ 171$ thousand, equal to $8 \%$ ). A relevant contribution of the present study is also due to the estimation costs strictly related to HPV virus. Although, the estimation was based on the literature $[1,5,10-13]$ and not on administrative data, it was possible to estimate that over $72 \%$ of the admissions related to hospitalizations were strictly linked to HPV. These hospitalizations caused a mean annual burden of about $€ 3,89$ million in Veneto and $€ 1,60$ million in Marche. Therefore, $67 \%$ of the estimated costs for the diseases being analysed can be strictly associated with the HPV virus in Veneto, while they account for $71 \%$ in Marche.

In conclusion, the present analysis may have some limitations. First of all, the regional hospital discharge forms may have codification problems; therefore some information may be missing and/or be wrongly reported. In this case, our analysis may have missed this information (due to the inclusion criteria), with the risk of underestimating the economic and epidemiological burden of the considered HPV-related diseases. Additionally, not all diseases led to hospitalization and this may be a further cause of underestimation. Therefore, the hospitalizations are underestimates of the generic prevalence referred to the population thus it may be assumed that the missing information does not significantly invalidate the results. Furthermore, due to a lack of available data, direct costs attributable to GPs additional treatments were not included as well as cost related to Recurrent Respiratory Papillomatosis (RRP) disease that, although rare, could be relevant to the overall estimate of the hospitalization costs of HPV induced malignancies. Lastly, it may be deemed that the reference time span (2008-2011) is too short, especially if compared to the previous study based only on Veneto [3], or the national burden estimates based on the literature. Being limited to two regions, the analysis may not be very significant. However, these regions accounted for almost $9 \%$ of the total number of patients in Italy and, for management and epidemiological characteristics, Marche and Veneto are two of the best-performing regions in terms of health service management. They may represent good examples to study the economic impact of the HPV-related diseases in Italy.

\section{Conclusions:}


This work represents a useful tool to quantify the economic burden of the HPV-related diseases in terms of hospitalizations. The expenses observed in the two regions represent a significant cost and management driver also in view of the decisions in terms of HPV prevention policies nationally.

\section{Compliance with ethical standards:}

Funding: The study was supported with unrestricted funding from Sanofi Pasteur MSD, Italy. Conflict of Interest: Francesco S. Mennini, Gianluca Fabiano, Andrea Marcellusi, Paolo Sciattella, Mario Saia, Silvia Cocchio and Vincenzo Baldo declare no conflicts of interest.

Ethical Approval: As this was a retrospective study, institutional ethics committee approval was not required.

\section{References:}

1. Clifford, G.M., et al., Human papillomavirus types in invasive cervical cancer worldwide: a meta-analysis. Br J Cancer, 2003. 88(1): p. 63-73.

2. Frazer, I.H., et al., Advances in prevention of cervical cancer and other human papillomavirus-related diseases. Pediatr Infect Dis J, 2006. 25(2 Suppl): p. S65-81, quiz S82.

3. Baldo, V., et al., Hospitalization for diseases attributable to human papillomavirus in the Veneto Region (North-East Italy). BMC Infect Dis, 2013. 13: p. 462.

4. Baio, G., et al., Economic burden of human papillomavirus-related diseases in Italy. PLoS One, 2012. 7(11): p. e49699.

5. de Martel, C., et al., Global burden of cancers attributable to infections in 2008: a review and synthetic analysis. Lancet Oncol, 2012. 13(6): p. 607-15.

6. D'Alo, D., et al., Epidemiology of HPV-related female cancers in the Umbria region of Italy: pre-vaccination period. Eur J Gynaecol Oncol, 2013. 34(4): p. 311-8.

7. Gasparini, R. and D. Panatto, Epidemiology, prevention and treatment of HPV infections and related pathologies in Italy: a comparison with the international context. Preface. Vaccine, 2009. 27 Suppl 1: p. A1.

8. Masia, G., et al., Epidemiology and genotype distribution of human papillomavirus (HPV) in women of Sardinia (Italy). Vaccine, 2009. 27 Suppl 1: p. A11-6.

9. Istituto Nazionale di Statistica (ISTAT). Popolazione residente al 1 Gennaio 2013. Statistiche Demografiche 2014; Available from: http://demo.istat.it/.

10. Dunne, E.F. and L.E. Markowitz, Genital human papillomavirus infection. Clin Infect Dis, 2006. 43(5): p. 624-9.

11. Insinga, R.P., E.J. Dasbach, and E.R. Myers, The health and economic burden of genital warts in a set of private health plans in the United States. Clin Infect Dis, 2003. 36(11): p. 1397-403.

12. Crow, J.M., HPV: The global burden. Nature, 2012. 488(7413): p. S2-3.

13. Kreimer, A.R., et al., Human papillomavirus types in head and neck squamous cell carcinomas worldwide: a systematic review. Cancer Epidemiol Biomarkers Prev, 2005. 14(2): p. 467-75.

14. Ferlay, J., et al., Estimates of worldwide burden of cancer in 2008: GLOBOCAN 2008. Int J Cancer, 2010. 127(12): p. 2893-917.

15. Vittori G, M.A., Boselli F, Naldi L, Emberti Gialloreti L A new approach to estimate Genital Warts incidence and prevalence in the Italian general female population. J Gynecol Obstet 2008. 20: p. p. 33-42. 
16. Salute, M.d., Rapporto annuale sull'attività di ricovero ospedaliero, D.G.d.P. sanitaria, Editor. 2015.

17. Salute, M.d., Piano Nazionale Prevenzione Vaccinale. 2016.

18. Marcellusi, A., Impact of HPV vaccination: health gains in the Italian female population. Popul Health Metr, 2017. 15(1): p. 36. 